\title{
Protective effect of ascorbic acid against ethanol-induced reproductive toxicity in male guinea pigs
}

\author{
R. Harikrishnan, P. A. Abhilash, S. Syam Das, P. Prathibha, S. Rejitha, Febi John, S. Kavitha \\ and M. Indira* \\ Department of Biochemistry, University of Kerala, Thiruvananthapuram 695 581, Kerala, India
}

(Submitted 11 June 2012 - Final revision received 26 November 2012 - Accepted 26 November 2012 - First published online 21 January 2013 )

\begin{abstract}
The present study was undertaken to elucidate the effect of ascorbic acid on alcohol-induced reproductive toxicity and also to compare it with that of abstention. A total of thirty-six male guinea pigs were divided into two groups and were maintained for $90 \mathrm{~d}$ as control and ethanol-treated groups ( $4 \mathrm{~g} / \mathrm{kg}$ body weight (b.wt.)). After $90 \mathrm{~d}$, ethanol administration was stopped and animals in the control group were divided into two groups and then maintained for $30 \mathrm{~d}$ as the control and control + ascorbic acid groups and those in the ethanol-treated group as ethanol abstention and ethanol + ascorbic acid $(25 \mathrm{mg} / 100 \mathrm{~g}$ b. wt.) groups. Animals treated with ethanol showed a significant decline in sperm quality $(P<0 \cdot 001)$, decreased activity of steroidogenic enzymes $(P<0 \cdot 05)$ and reduced serum testosterone $(P<0 \cdot 05)$, luteinising hormone and follicle-stimulating hormone levels, decrease in the activity of testicular succinate dehydrogenase, adenosine triphosphatase, sorbitol dehydrogenase and reduction in fructose content $(P<0.05)$. It also caused an increase in testicular malondialdehyde levels $(P<0.05)$ and decrease in the levels of glutathione content $(P<0.001)$ of testes. Ascorbic acid levels in testes and plasma were also reduced $(P<0.001)$ in ethanol-fed animals. Ascorbic acid supplementation altered all these parameters and produced a better and faster recovery from alcohol-induced reproductive toxicity than abstention. The mechanism of action of ascorbic acid may be by reducing the oxidative stress and improving antioxidant status, which eventually changed the microenvironment of testes and enhanced the energy needed for motility of sperms, improved the sperm morphology and elevated the testosterone and gonadotropin levels.
\end{abstract}

\section{Key words: Alcoholism: Reproductive toxicity: Ascorbic acid: Abstention}

Chronic alcoholism exerts toxic effects on the male reproductive system ${ }^{(1)}$. Chronic and persistent alcohol use is known to induce sexual dysfunction ${ }^{(2)}$. Prolonged alcohol abuse in men can cause testosterone deficiency and testicular atrophy, which can lead to impotence, sterility and feminisation ${ }^{(3)}$. Alcohol is well documented as a direct testicular toxin ${ }^{(4)}$ and can cause significant deterioration in sperm concentration, motility and morphology in alcoholic men ${ }^{(5,6)}$. Numerous experimental data indicate that free radical mechanisms contribute to ethanol-induced testicular alterations ${ }^{(7)}$. Animal studies have indicated that depletion in antioxidant status occurs as a result of oxidative stress due to excess alcohol intake ${ }^{(8,9)}$.

Ascorbic acid or L-ascorbate is a major water-soluble chainbreaking antioxidant that is able to neutralise free radicals. It is essential for the maintenance of the structural and functional integrity of testes ${ }^{(10)}$. Ascorbic acid plays a significant role in semen integrity and fertility, both in human subjects ${ }^{(11,12)}$ and experimental animals ${ }^{(13)}$, and contributes to about $65 \%$ of the total antioxidant capacity of seminal plasma found intracellularly and extracellularly ${ }^{(14)}$. Guinea pigs maintained on a high-ascorbic acid diet showed reduction in ethanol-induced toxicity as compared with low ascorbic acid-supplemented animals. High dietary levels of ascorbic acid were found to be protective against hepatic steatosis, necrosis and elevated levels of serum glutamate oxaloacetate transaminase and serum glutamate pyruvate transaminase in guinea pigs caused by chronic ethanol consumption ${ }^{(15)}$

Although significant progress has been made in understanding the pathogenesis of alcoholic testicular damage, treatment options are limited. At present, abstention from taking alcohol seems to be the only effective therapy adopted to bring down the toxic effects of alcohol. Hence, an effective and economic way to overcome the alterations induced by chronic alcohol abuse has become important. Earlier studies conducted in

Abbreviations: $3 \beta$-HSD, 3 $\beta$-hydroxysteroid dehydrogenase; $17 \beta$-HSD, 17 $\beta$-hydroxysteroid dehydrogenase; ATPase, adenosine triphosphatase; b.wt., body weight; C, control; C + AA, control + ascorbic acid; E, ethanol-treated group; EAG, ethanol abstention group; E + AA, ascorbic acid supplemented group; FSH, follicle-stimulating hormone; GGT, $\gamma$-glutamyl transpeptidase; GSH, glutathione; LH, luteinising hormone; MDA, malondialdehyde; SDH, succinate dehydrogenase; SORD, sorbitol dehydrogenase.

*Corresponding author: M. Indira, fax +91 471 2308078, email indiramadambath@gmail.com 
our laboratory have shown that ascorbic acid mitigates alcohol-induced hepatotoxicity ${ }^{(16)}$. Hence, we extended our studies to analyse the impact of ascorbic acid on ethanolinduced reproductive toxicity. Animal models have been developed to study chronic alcohol abuse by the oral administration of alcohol. Like human beings, guinea pigs are unable to synthesise ascorbic acid due to the lack of a key biosynthetic enzyme, L-gulonolactone oxidase ${ }^{(17)}$. The present study investigated the effect of ascorbic acid supplementation during abstention in chronic alcoholic guinea pigs on reproductive toxicity and compared it with those animals in abstention.

\section{Materials and methods}

\section{Experimental animals}

Sexually matured male guinea pigs (Cavia porcellus) of Hartley strain, weighing between 400 and $450 \mathrm{~g}$, procured from Small animals breeding station, Mannuthy, Thrissur, Kerala, India, were used. The animals were maintained under standard animal husbandry conditions. The animals were housed in polypropylene cages, kept under controlled conditions of temperature of $28 \pm 2{ }^{\circ} \mathrm{C}, 45-60 \%$ relative humidity and exposed to a $12 \mathrm{~h}$ dark $-12 \mathrm{~h}$ light cycle. Male guinea pigs were fed with guinea pig feed (Sai Feeds) and water was given ad libitum. The study protocol was approved by the institutional animal ethics committee (IAEC-KU-6/09-10-BC-MI (21)). Animals were handled using the laboratory animal welfare guidelines ${ }^{(18)}$. Absolute alcohol was purchased from M/s Merck Limited. Ethanol diluted with distilled water (1:1, v/v) was given by oral administration. Ascorbic acid was purchased from M/s SRL Limited. Ascorbic acid was freshly dissolved in distilled water during treatment and given orally by gastric tube.

\section{Experimental design}

Phase I: Dose-dependent studies. Dose-dependent studies were carried out to find the optimum dose of ascorbic acid to be given for regression of alcohol-induced testicular toxicity.

Groups. A total of forty-two guinea pigs were first grouped into two and maintained for $90 \mathrm{~d}$ as follows: group 1: control (C1) ( $n$ 12) and group 2: ethanol treated ( $4 \mathrm{~g} / \mathrm{kg}$ body weight (b.wt.)/d) (E) ( $n$ 30). The dose of alcohol was selected from previous studies ${ }^{(19)}$. Animals in the control group were given glucose solution equivalent to the energy supplied by ethanol (isoenergetic). Ethanol administration was stopped after $90 \mathrm{~d}$, and six animals in the ethanol-treated group and the control group were killed after overnight fasting and the testis and the blood were collected for biochemical analysis. The animals in the ethanol-treated group were further divided into four groups of six guinea pigs each to which ascorbic acid of different doses was supplemented: E + AA ( $1 \mathrm{mg} / 100 \mathrm{~g}$ b.wt.) ( $n$ 6), E + AA (10 mg/100 g b.wt.) ( $n$ 6), $\mathrm{E}+\mathrm{AA}$ ( $25 \mathrm{mg} / 100 \mathrm{~g}$ b.wt.) ( $n$ 6) and $\mathrm{E}+\mathrm{AA}(50 \mathrm{mg} / 100 \mathrm{~g}$ b.wt.) ( $n$ 6). The remaining animals in the control group (C2) ( $n$ 6) were fed with a normal diet. The period of regression was $30 \mathrm{~d}$. Previous studies ${ }^{(16)}$ in our laboratory have shown that administration of ethanol for $90 \mathrm{~d}$, at a dose of $4 \mathrm{~g} / \mathrm{kg}$ b.wt., is ideal to create a chronic alcohol model, and reversal for $30 \mathrm{~d}$ using ascorbic acid has been effective in protection against alcohol-induced hepatotoxicity. Hence, the duration of the study was $90 \mathrm{~d}$ for toxicity induction and $30 \mathrm{~d}$ for reversal. The experimental design is schematically represented in Fig. 1.

At the end of the experimental period, animals were fasted overnight, anaesthetised by ketamine hydrochloride and then killed. The testes were dissected out and cleaned with ice-cold PBS, blotted dry and immediately transferred to ice-cold containers for biochemical and sperm characteristic analysis. Blood was collected for various biochemical analyses.

Phase II. A total of thirty-six guinea pigs were first grouped into two: group 1: control (C) ( $n$ 18) and group 2: ethanol ( $4 \mathrm{~g} / \mathrm{kg}$ b.wt./d) treated (E) ( $n$ 18). Alcohol at a dose of $4 \mathrm{~g} / \mathrm{kg}$ b.wt. was given for a period of $90 \mathrm{~d}$. The control group was given isoenergetic glucose solution. Blood was collected weekly from the ear of guinea pigs, and the weekly progression and regression of ethanol toxicity was assessed by assaying the activity of the toxicity marker, $\gamma$-glutamyl transpeptidase (GGT), in serum. After $90 \mathrm{~d}$, ethanol administration was stopped and six animals each from the control and the ethanol-treated groups were killed after overnight fasting. The control group was used to evaluate whether the toxicity was induced after $90 \mathrm{~d}$ of alcohol administration in the ethanol-treated group by the assay of liver function markers alanine aminotransferase, aspartate aminotransferase and GGT in serum. All other parameters were analysed only in the ethanol-treated group. The blood was collected and the testis and accessory reproductive organs, epididymis and seminal vesicle, were dissected from the ethanol-treated group for various biochemical analysis. The remaining animals in the control group were maintained as control (C) ( $n$ 6) and ascorbic acid-treated groups (C + AA) ( $25 \mathrm{mg} / 100 \mathrm{~g}$ b.wt.) ( $n$ 6) and the remaining animals in the ethanol-treated group were further divided into two groups as the ascorbic acid-treated groups (E + AA) $(25 \mathrm{mg} / 100 \mathrm{~g}$ b.wt) ( $n$ 6) and the ethanol abstention group (EAG) $(n 6)$. The experimental design is schematically represented in Fig. 2.

The dose of ascorbic acid was selected from phase I studies. The period of regression was $30 \mathrm{~d}$. At the end of the experimental period $(90+30 \mathrm{~d})$, animals were fasted overnight, anaesthetised by ketamine hydrochloride and then killed. The testis, epididymis and seminal vesicle were removed and their absolute and relative b.wt. (relative b.wt. = organ weight/final b.wt. $\times 100$ ) were determined. The testis was dissected out and cleaned with ice-cold PBS, blotted dry and immediately transferred to ice-cold containers for various biochemical evaluations. Blood was collected in clean, dry testtubes, and allowed to clot at room temperature. The clear serum was removed after centrifugation and used immediately for the assay of alanine aminotransferase, aspartate aminotransferase and GGT and stored at $-20^{\circ} \mathrm{C}$ until the assay of hormones. For plasma, blood was collected in heparinised tubes, centrifuged at $3000 \mathrm{~g}$ for $10 \mathrm{~min}$ and stored at $-20^{\circ} \mathrm{C}$ for HPLC analysis of ascorbic acid. 


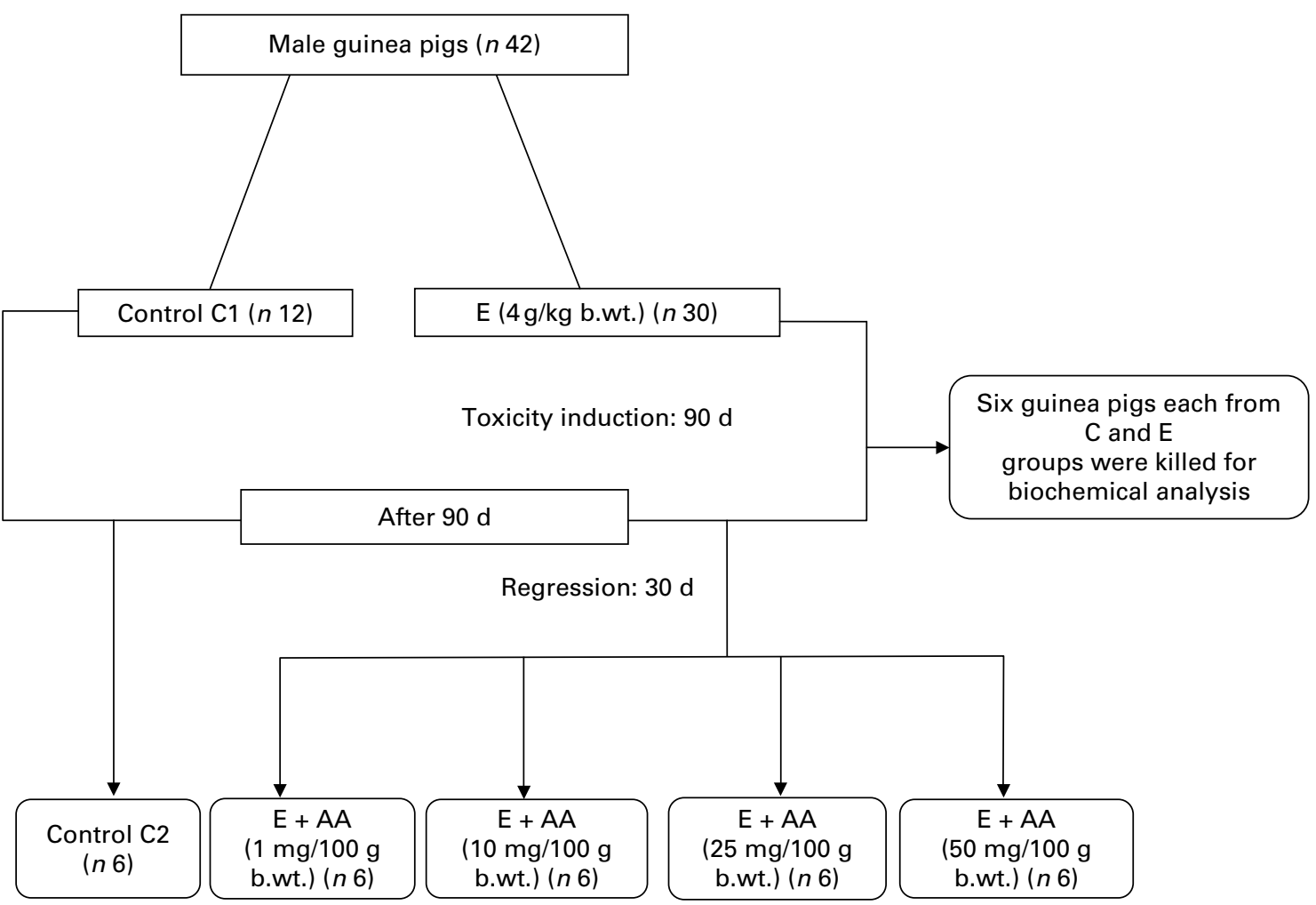

Fig. 1. Schematic representation of experimental design of phase I study. C, control group; E, ethanol-treated group; b.wt., body weight; $\mathrm{E}+\mathrm{AA}$, ascorbic acidsupplemented group.

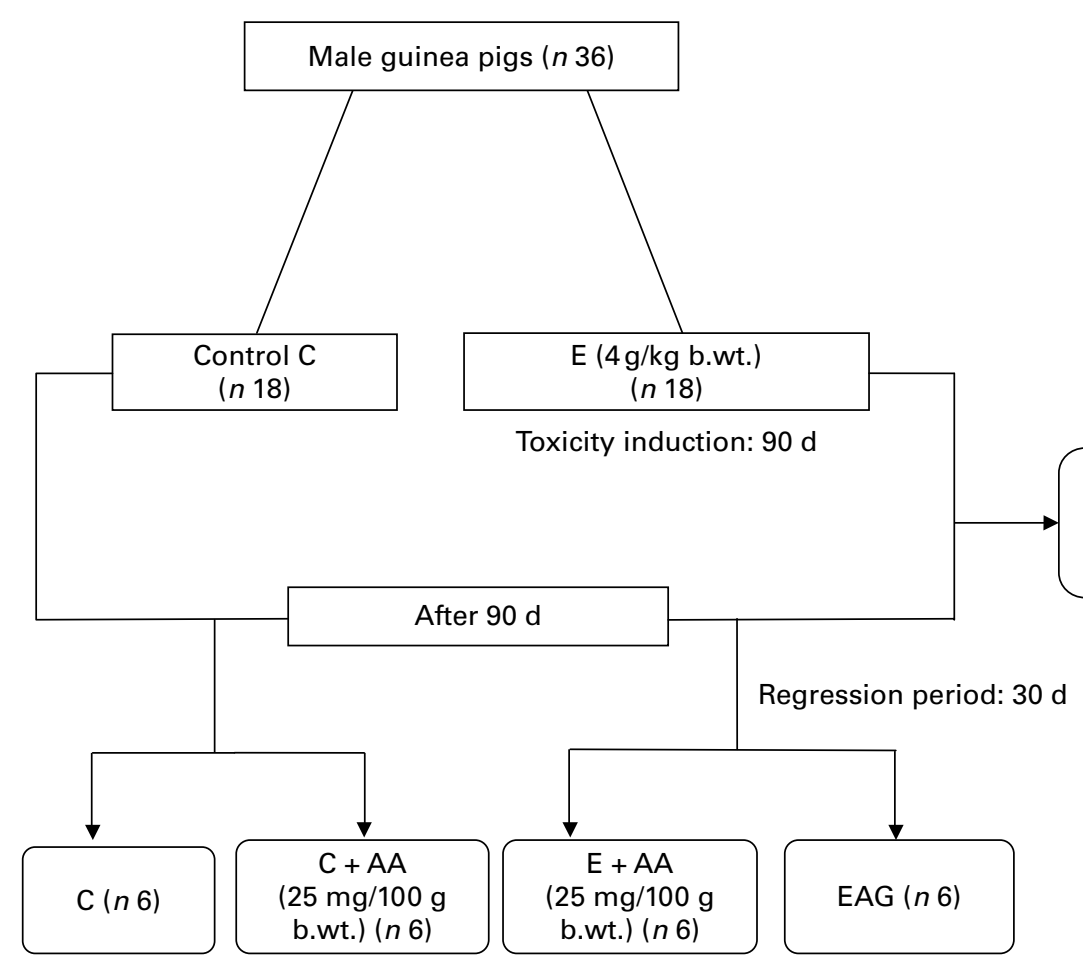

Six guinea pigs each from $\mathrm{C}$ and $\mathrm{E}$ groups were killed for biochemical analysis

Fig. 2. Schematic representation of experimental design of phase II study. C, control group; $E$, ethanol-treated group; b.wt., body weight; $C+A A$, control + ascorbic acid group; $E+A A$, ascorbic acid-supplemented group; EAG, ethanol abstention group. 


\section{Methods}

Semen characteristics. Seminal content of epididymis was obtained by cutting the cauda epididymis using surgical blades and squeezed onto a sterile clean watch glass. This content was diluted ten times with $2.9 \%$ sodium citrate dehydrate solution and thoroughly mixed to estimate the percentage progressive motility and sperm concentration ${ }^{(20)}$. One drop of the suspension was smeared on a glass slide and stained by eosin-nigrosin stain to determine the percentage of sperm cell viability and morphological abnormalities ${ }^{(20)}$.

Biochemical parameters. Activity of alanine aminotransferase, aspartate aminotransferase ${ }^{(21)}$ and $\mathrm{GGT}^{(22)}$ in serum was assayed. Succinate dehydrogenase (SDH) activity ${ }^{(23)}$ and adenosine triphosphatase (ATPase) activity in testes ${ }^{(24)}$ were estimated. Activity of sorbitol dehydrogenase (SORD) in seminal vesicle ${ }^{(25)}$ and the seminal fructose content ${ }^{(26)}$ were determined. Glutathione (GSH) content ${ }^{(27)}$ and ascorbic acid levels in testes ${ }^{(28)}$ were measured. Malondialdehyde (MDA) levels ${ }^{(29)}$ and total protein in testes ${ }^{(30)}$ were estimated.

Assay of serum testosterone, luteinising hormone and follicle-stimulating hormone. Serum testosterone was assayed using a solid-phase RIA kit obtained from the Diagnostic Products Corporation. The sensitivity of the testosterone assay was $4 \mathrm{pg} / \mathrm{l}$. Follicle-stimulating hormone (FSH) and luteinising hormone (LH) were measured using an electrochemiluminescence immunoassay using a Boehringer Manheim Elecsys 2010 Immuno analyser (Roche Diagnostics). The detection limits were $0 \cdot 10 \mathrm{mIU} / \mathrm{ml}$ for FSH and $\mathrm{LH}$.

Determination of ascorbic acid in plasma by HPLC. One part plasma with four parts of $6 \%$ metaphosphoric acid were mixed in a polypropylene storage vial. The vial contents were vortexed and centrifuged at $10000 \boldsymbol{g}$ for $15 \mathrm{~min}$ at $4^{\circ} \mathrm{C}$ and the supernatant was used for analysis. HPLC analysis was done by the Shimadzu Prominence SCL-20AHT (Shimadzu) system and the separation of ascorbic acid was done by isocratic gradient elution using a Luna 5S NH2 100A column (Phenomenex). The length of the column was $250 \mathrm{~mm} \times 4.6 \mathrm{~mm}$ and the particle size was $5 \mu \mathrm{m}$. The mobile phase was HPLC-grade water (eluent A) and methanol (eluent $\mathrm{B}$ ) in a 1:1 ratio, the total flow rate was $1.0 \mathrm{ml}$ per min and the time of analysis was $15 \mathrm{~min}$. The detector's wavelengths were set at $268 \mathrm{~nm}$. The injection volume was $20 \mu \mathrm{l}$ and the temperature of the column was thermostated at $40^{\circ} \mathrm{C}$.

Assay of $3 \beta$-hydroxysteroid dehydrogenase and $17 \beta$-hydroxysteroid dehydrogenase. Assay of $3 \beta$-hydroxysteroid dehydrogenase ( $3 \beta$-HSD) was carried out according to the colorimetric assay of Shivanandappa \& Venkatesh ${ }^{(31)}$. Tissue was homogenised in $0 \cdot 1 \mathrm{M}$-Tris- $\mathrm{HCl}$ and centrifuged at $12000 \mathrm{~g}$ at $40^{\circ} \mathrm{C}$. To $0.05 \mathrm{ml}$ homogenate, $1 \mathrm{ml} \mathrm{NAD}, 1 \mathrm{ml}$ dehydroepiandrosterone (DHEA) and $0.9 \mathrm{ml}$ water were added and incubated for $1 \mathrm{~h}$ at $37^{\circ} \mathrm{C}$. The reaction was stopped using $2 \mathrm{ml}$ phthalate buffer. The turbidity was removed by centrifugation at $1000 \boldsymbol{g}$ for $20 \mathrm{~min}$. Supernatant was read at $490 \mathrm{~nm}$. Activity of $17 \beta$-hydroxysteroid dehydrogenase (17 $\beta$-HSD) was measured according to the method of Jarbak et al. ${ }^{(32)}$. The testicular supernatant $(1 \mathrm{ml})$ was mixed with $440 \mu \mathrm{M}$ of sodium pyrophosphate buffer ( $\mathrm{pH}$ 10.2), $25 \mathrm{mg}$ crystalline bovine serum albumin and $0.3 \mu \mathrm{m}$ of testosterone. The total volume was made up to $3 \mathrm{ml}$. Enzyme activity was measured after the addition of $1.1 \mu \mathrm{m}-\mathrm{NADP}$ to the incubation mixtures in a spectrophotometer at $340 \mathrm{~nm}$. For a detailed description of the procedures, see Supplementary material (available online).

\section{Statistical analysis}

Data are presented as means with their standard errors. The degree of significance was set at $P<0 \cdot 05$. One-way ANOVA and post hoc Tukey-honestly significant difference test were used to determine the differences among the groups. All the analyses were carried out using the SPSS/PC (version 17.0; SPSS) software package program.

\section{Results}

Phase I

The dose-dependent studies showed (Table 1) that animals supplemented with ascorbic acid at a dose of $25 \mathrm{mg} / 100 \mathrm{~g}$ b.wt. and $50 \mathrm{mg} / 100 \mathrm{~g}$ b.wt. showed significant $(P<0 \cdot 001)$

Table 1. Effect of different doses of ascorbic acid supplementation after alcohol administration on sperm count, testicular malondialdehyde (MDA) and serum $\gamma$-glutamyl transpeptidase (GGT) (phase I study)

(Mean values with their standard errors of six guinea pigs in each group)

\begin{tabular}{|c|c|c|c|c|c|c|}
\hline \multirow[b]{2}{*}{ Groups } & \multicolumn{2}{|c|}{$\begin{array}{l}\text { Sperm count (mil- } \\
\text { lions } / \mathrm{ml} \text { ) }\end{array}$} & \multicolumn{2}{|c|}{$\begin{array}{c}\text { Testicular MDA } \\
\text { (m mol/100 g tissue) }\end{array}$} & \multicolumn{2}{|c|}{ Serum GGT (IU/ml) } \\
\hline & Mean & SEM & Mean & SEM & Mean & SEM \\
\hline C1 & $44 \cdot 4^{\mathrm{a}}$ & $4 \cdot 3$ & $1.58^{\mathrm{a}}$ & 0.15 & $6 \cdot 39^{\mathrm{a}}$ & 0.61 \\
\hline E & $24 \cdot 4^{\mathrm{b}}$ & $2 \cdot 4$ & $3 \cdot 12^{\mathrm{b}}$ & 0.30 & $19 \cdot 12^{b}$ & $2 \cdot 31$ \\
\hline $\mathrm{C} 2$ & $43.7^{\mathrm{a}}$ & 3.5 & $1.62^{\mathrm{a}}$ & 0.16 & $6.78^{\mathrm{a}}$ & 0.74 \\
\hline $\mathrm{E}+\mathrm{AA}(1 \mathrm{mg} / 100 \mathrm{~g}$ b.wt.) & $25 \cdot 7^{\mathrm{b}}$ & 2.5 & $2.95^{\mathrm{d}}$ & 0.28 & $16 \cdot 72^{\mathrm{c}}$ & 1.60 \\
\hline $\mathrm{E}+\mathrm{AA}(10 \mathrm{mg} / 100 \mathrm{~g}$ b.wt. $)$ & $29 \cdot 0^{\mathrm{b}}$ & 2.6 & $2 \cdot 80^{d}$ & 0.28 & $14 \cdot 14^{\mathrm{C}}$ & 1.60 \\
\hline $\mathrm{E}+\mathrm{AA}(25 \mathrm{mg} / 100 \mathrm{~g}$ b.wt. $)$ & $39 \cdot 0^{\mathrm{a}}$ & 3.1 & $2 \cdot 18^{\mathrm{C}}$ & 0.21 & $7 \cdot 85^{a}$ & 0.74 \\
\hline $\mathrm{E}+\mathrm{AA}(50 \mathrm{mg} / 100 \mathrm{~g}$ b.wt.) & $38 \cdot 2^{\mathrm{a}}$ & 3.0 & $2.30^{\mathrm{c}}$ & 0.19 & $8.71^{\mathrm{a}}$ & 0.83 \\
\hline
\end{tabular}

C1, control group maintained for first $90 \mathrm{~d}$; $\mathrm{E}$, ethanol-treated group; $\mathrm{C} 2$, control group maintained for last $30 \mathrm{~d}$; $\mathrm{E}+\mathrm{AA}(1 \mathrm{mg} / 100 \mathrm{~g}$ b.wt.), $1 \mathrm{mg} / 100 \mathrm{~g}$ body weight ascorbic acid-supplemented group; E+AA (10 mg/100 g b.wt.), $10 \mathrm{mg} / 100 \mathrm{~g}$ body weight ascorbic acid-supplemented group; E+AA $(25 \mathrm{mg} / 100 \mathrm{~g}$ b.wt.), $25 \mathrm{mg} / 100 \mathrm{~g}$ body weight ascorbic acid-supplemented group; E+AA ( $50 \mathrm{mg} / 100 \mathrm{~g}$ b.wt.), $50 \mathrm{mg} / 100 \mathrm{~g}$ body weight ascorbic acid-supplemented group.

a,b,c,d Mean values within a column with unlike superscript letters were significantly different $(P<0.05)$ 
Table 2. Activities of alanine aminotransferase (ALT), aspartate aminotransferase (AST) and $\gamma$-glutamyl transpeptidase (GGT) in serum after $90 \mathrm{~d}$ of alcohol administration (phase II study)

(Mean values with their standard errors of six guinea pigs in each group)

\begin{tabular}{|c|c|c|c|c|c|c|}
\hline \multirow[b]{2}{*}{ Groups } & \multicolumn{2}{|c|}{$\begin{array}{c}\text { ALT in serum } \\
\text { ( } \mu \mathrm{mol} \text { of pyruvate } \\
\text { liberated/min per } \\
\mathrm{mg} \text { protein) }\end{array}$} & \multicolumn{2}{|c|}{$\begin{array}{l}\text { AST in serum } \\
\text { ( } \mu \text { mol of oxaloa- } \\
\text { cetate liberated/ } \\
\text { min per mg } \\
\text { protein) }\end{array}$} & \multicolumn{2}{|c|}{$\begin{array}{l}\text { Serum GGT } \\
(\mathrm{IU} / \mathrm{ml})\end{array}$} \\
\hline & Mean & SEM & Mean & SEM & Mean & SEM \\
\hline C & $174.46^{\mathrm{a}}$ & $6 \cdot 18$ & $132 \cdot 25^{\mathrm{a}}$ & $13 \cdot 20$ & $5 \cdot 36^{\mathrm{a}}$ & 0.82 \\
\hline $\mathrm{E}$ & $241.00^{\mathrm{b}}$ & $19 \cdot 28$ & $268 \cdot 57^{b}$ & $24 \cdot 13$ & $18 \cdot 14^{\mathrm{b}}$ & 1.45 \\
\hline
\end{tabular}

C, control group; E, ethanol-treated group.

a,b Mean values within a column with unlike superscript letters were significantly different $(P<0.05)$

revival in sperm count and a decrease in elevated testicular MDA levels induced by ethanol administration, as compared with the control. The maximum effect was shown by the group supplemented with $25 \mathrm{mg} / 100 \mathrm{~g}$ b.wt. ascorbic acid. The low dose groups ( 1 and $10 \mathrm{mg} / 100 \mathrm{~g}$ b.wt. ascorbic acid) did not significantly restore the sperm count and testicular MDA levels. The activity of the toxicity marker, GGT, in serum, which was increased significantly $(P<0.001)$ in the alcohol-ingested group, was reduced significantly $(P<0 \cdot 001)$ in groups supplemented with 25 and $50 \mathrm{mg} / 100 \mathrm{~g}$ b.wt. of ascorbic acid and maximum recovery was shown by the group supplemented with $25 \mathrm{mg} / 100 \mathrm{~g}$ b.wt. of ascorbic acid.

\section{Phase II}

The liver function markers alanine aminotransferase, aspartate aminotransferase and GGT (Table 2) in serum increased significantly $(P<0.001)$ in the ethanol-treated group when compared with the control.

The b.wt. of guinea pigs (Table 3 ) decreased significantly $(P<0.05)$ in the alcohol-administered group when compared with the control. The b.wt. of both the $\mathrm{E}+\mathrm{AA}$ and EAG groups increased significantly $(P<0 \cdot 01)$. However, the change in b.wt. in the ascorbic acid-supplemented group $(P<0 \cdot 001)$ was significantly higher than in the EAG group.
The relative weight of testes and epididymis (Table 3) decreased significantly $(P<0.05)$ in the ethanol-administered group, as compared with the control. The relative weight of these organs increased on ascorbic acid administration. The abstention group also showed an increase in relative testicular weight but was less significant when compared with the ascorbic acid-supplemented group. However, the abstention group showed an increase in relative epididymal weight similar to the ascorbic acid-supplemented group. No significant change was observed in relative organ weights of the seminal vesicle.

GGT in serum during the treatment period (Fig. 3) showed a gradual increase in activity upon administration of ethanol. Both ascorbic acid supplementation and abstention significantly $(P<0.05)$ decreased the activity of GGT. However, a faster recovery was observed in the $\mathrm{E}+\mathrm{AA}$ group than with abstention.

Sperm parameters, like percentage sperm motility, sperm count and viability (Table 4), decreased significantly $(P<0.001)$ in the ethanol-treated guinea pigs. The percentage of abnormal sperms with marked morphological defects, like headless sperm, double-headed sperm, tailless sperm, looped tail and coiled tail sperms, increased significantly in the ethanol-treated group, as compared with the control. The sperm parameters were restored on ascorbic acid administration. Abstention was also able to reverse the sperm parameters, but was less significant when compared with the ascorbic acid-treated group.

The lipid peroxidation product, MDA (Table 5), increased significantly $(P<0.05)$ in the alcohol-ingested group when compared with the control, which was reduced on ascorbic acid supplementation. The MDA concentration also showed a decline in the abstention group, but was less pronounced when compared with the ascorbic acid-supplemented group.

The concentrations of testicular GSH content and ascorbic acid in testes (Table 5) and plasma (Fig. 4) were reduced significantly $(P<0 \cdot 001)$ in the ethanol-loaded group, which were restored to near-normal levels on ascorbic acid administration. Abstention could also increase the levels of GSH and ascorbic acid, but to a lesser extent when compared with the ascorbic acid-supplemented group.

Table 3. Body and reproductive organ weights (phase II study)

(Mean values with their standard errors of six guinea pigs in each group)

\begin{tabular}{|c|c|c|c|c|c|c|c|c|c|c|}
\hline \multirow[b]{2}{*}{ Parameters } & \multicolumn{2}{|c|}{ C } & \multicolumn{2}{|c|}{$\mathrm{C}+\mathrm{AA}$} & \multicolumn{2}{|c|}{$\mathrm{E}$} & \multicolumn{2}{|c|}{ EAG } & \multicolumn{2}{|c|}{$E+A A$} \\
\hline & Mean & SEM & Mean & SEM & Mean & SEM & Mean & SEM & Mean & SEM \\
\hline Initial body weight (g) & $436^{a}$ & $4 \cdot 0$ & $430^{\mathrm{a}}$ & 3.0 & $445^{\mathrm{a}}$ & $4 \cdot 0$ & $448^{\mathrm{a}}$ & $4 \cdot 0$ & $427^{a}$ & $3 \cdot 0$ \\
\hline Final body weight $(\mathrm{g})$ & $638^{\mathrm{a}}$ & $5 \cdot 0$ & $653^{\mathrm{a}}$ & 3.0 & $464^{\mathrm{b}}$ & $4 \cdot 0$ & $506^{\mathrm{c}}$ & $4 \cdot 0$ & $609^{d}$ & $5 \cdot 0$ \\
\hline Change in body weight $(\mathrm{g})$ & $204^{\mathrm{a}}$ & $2 \cdot 0$ & $223^{\mathrm{b}}$ & $2 \cdot 0$ & $19^{c}$ & 0.50 & $61^{\mathrm{d}}$ & 1.0 & $174^{\mathrm{e}}$ & $2 \cdot 0$ \\
\hline Testes $(\mathrm{g})$ & $2 \cdot 69^{a}$ & 0.09 & $2 \cdot 88^{a}$ & 0.10 & $1 \cdot 26^{b}$ & 0.04 & $1 \cdot 82^{c}$ & 0.06 & $2 \cdot 49^{\mathrm{a}}$ & 0.11 \\
\hline Relative weight of testes ( $\mathrm{g} / 100 \mathrm{~g}$ b.wt.) & $0.42^{\mathrm{a}}$ & 0.04 & $0.44^{\mathrm{a}}$ & 0.04 & $0.27^{b}$ & 0.02 & $0.36^{c}$ & 0.03 & $0.41^{d}$ & 0.04 \\
\hline Epididymis $(\mathrm{g})$ & $0.74^{\mathrm{a}}$ & 0.02 & $0.83^{\mathrm{a}}$ & 0.03 & $0.44^{b}$ & 0.01 & $0.55^{b}$ & 0.02 & $0.69^{a}$ & 0.02 \\
\hline Relative weight of epididymis (g/100 g b.wt.) & $0.12^{\mathrm{a}}$ & 0.02 & $0.11^{\mathrm{a}}$ & 0.02 & $0.09^{b}$ & 0.03 & $0 \cdot 11^{\mathrm{a}}$ & 0.02 & $0.11^{\mathrm{a}}$ & 0.03 \\
\hline Seminal vesicle $(\mathrm{g})$ & $0.82^{\mathrm{a}}$ & 0.03 & $0.91^{\mathrm{b}}$ & 0.03 & $0.63^{\mathrm{c}}$ & 0.02 & $0.69^{\mathrm{c}}$ & 0.02 & $0.77^{\mathrm{a}}$ & 0.02 \\
\hline Relative weight of seminal vesicle ( $g / 100 \mathrm{~g}$ b.wt.) & $0.13^{a}$ & 0.01 & $0.14^{\mathrm{a}}$ & 0.02 & $0.14^{\mathrm{a}}$ & 0.02 & $0.14^{\mathrm{a}}$ & 0.01 & $0.13^{\mathrm{a}}$ & 0.01 \\
\hline
\end{tabular}

C, control group; $\mathrm{C}+\mathrm{AA}$, control + ascorbic acid group; E, ethanol-treated group; EAG, ethanol abstention group; $\mathrm{E}+\mathrm{AA}$, ascorbic acid-supplemented group; b.wt., body weight. a,b,c,d Mean values within a row with unlike superscript letters were significantly different $(P<0 \cdot 05)$. 
Table 4. Sperm characteristic analysis (phase II study)

(Mean values with their standard errors of six guinea pigs in each group)

\begin{tabular}{|c|c|c|c|c|c|c|c|c|}
\hline \multirow[b]{2}{*}{ Groups } & \multicolumn{2}{|c|}{$\begin{array}{c}\text { Sperm motility } \\
(\%)\end{array}$} & \multicolumn{2}{|c|}{$\begin{array}{l}\text { Sperm count } \\
\text { (millions/ml) }\end{array}$} & \multicolumn{2}{|c|}{$\begin{array}{c}\text { Sperm viability } \\
(\%)\end{array}$} & \multicolumn{2}{|c|}{$\begin{array}{c}\text { Sperm } \\
\text { abnormalities } \\
(\%)\end{array}$} \\
\hline & Mean & SEM & Mean & SEM & Mean & SEM & Mean & SEM \\
\hline C & $96 \cdot 8^{a}$ & 3.6 & $46 \cdot 8^{a}$ & 1.8 & $98.0^{a}$ & 3.5 & $1 \cdot 2^{\mathrm{a}}$ & 0.04 \\
\hline $\mathrm{C}+\mathrm{AA}$ & $98 \cdot 4^{\mathrm{a}}$ & 3.7 & $44 \cdot 4^{\mathrm{a}}$ & 1.7 & $94.6^{\mathrm{a}}$ & 3.5 & $1 \cdot 1^{\mathrm{a}}$ & 0.03 \\
\hline $\mathrm{E}$ & $58 \cdot 3^{\mathrm{b}}$ & $2 \cdot 1$ & $33 \cdot 3^{\mathrm{b}}$ & 1.2 & $53 \cdot 4^{b}$ & 2.0 & $8 \cdot 6^{\mathrm{b}}$ & 0.3 \\
\hline EAG & $75 \cdot 0^{C}$ & $2 \cdot 8$ & $37.8^{\mathrm{b}}$ & 1.4 & $67 \cdot 7^{\mathrm{c}}$ & $2 \cdot 4$ & $6 \cdot 1^{c}$ & 0.2 \\
\hline $\mathrm{E}+\mathrm{AA}$ & $87 \cdot 8^{a}$ & 3.3 & $41 \cdot 6^{a}$ & 1.5 & $80 \cdot 3^{d}$ & 3.0 & $3 \cdot 9^{d}$ & 0.1 \\
\hline
\end{tabular}

$C$, control group; $C+A A$, control + ascorbic acid group; $E$, ethanol-treated group; $E A G$, ethanol abstention group; $\mathrm{E}+\mathrm{AA}$, ascorbic acid-supplemented group.

a,b,c,d Mean values within a column with unlike superscript letters were significantly different $(P<0.05)$.

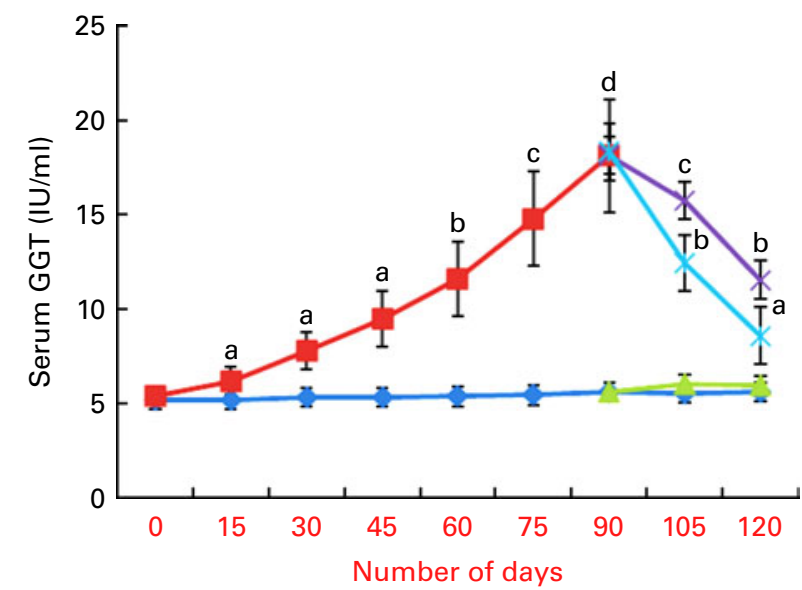

Fig. 3. Time-course measurement of activity of $\gamma$-glutamyl transpeptidase in serum. Values are means, with their standard errors of six guinea pigs in each group represented by vertical bars. ${ }^{\mathrm{a}, \mathrm{b}, \mathrm{c}, \mathrm{d}}$ Mean values with unlike letters were significantly different $(P<0.05)$. C $(-)$, control group; $\mathrm{C}+\mathrm{AA}(-)$, control + ascorbic acid group; E $(-)$, ethanol-treated group; EAG $(-)$, ethanol abstention group; $E+A A(-)$, ascorbic acid-supplemented group. (A colour version of this figure can be found online at http://www.journals. cambridge.org/bjn).

Serum testosterone, LH and FSH levels (Table 6) were significantly reduced $(P<0 \cdot 05)$ in the alcohol-administered group, but were elevated on ascorbic acid supplementation. Abstention did not significantly improve the testosterone concentration and gonadotropin levels, as compared with the ascorbic acid-treated group.

The activities of key steroidogenic enzymes, $3 \beta-\mathrm{HSD}$ and $17 \beta$-HSD (Table 7$)$, were reduced significantly $(P<0.05)$ in the ethanol-administered group, as compared with the control. The activities of these enzymes increased significantly $(P<0.05)$ in the ascorbic acid-administered group and with abstention. The increase in the activities was more pronounced in the ascorbic acid-supplemented group when compared with abstention.

The concentration of fructose (Table 7) in seminal plasma and activity of SORD in seminal vesicle were reduced significantly $(P<0.05)$ in the alcohol-administered group, as compared with the control. Ascorbic acid supplementation significantly $(P<0.05)$ increased their concentration compared with the abstention group.

The SDH and ATPase activity (Table 7) in testes dropped significantly $(P<0.05)$ in the alcohol-fed group when compared with the control. Their activities were brought back to near-normal level by the administration of ascorbic acid. Abstention also increased their activities, but was less significant compared with the ascorbic acid-fed group.

\section{Discussion}

Earlier reports ${ }^{(14)}$ have implicated the role of reactive oxygen species-mediated oxidative stress in the pathophysiology of alcohol-mediated reproductive toxicity. Numerous studies are available regarding the effect of ascorbic acid on alcohol-induced hepatotoxicity. However, very less information is available regarding the effect of ascorbic acid in alcohol-mediated testicular dysfunctions in scorbutic animal models. Ascorbic acid is one of the important and essential vitamins for human health. It functions physiologically as a

Table 5. Effect of ascorbic acid supplementation and abstention after alcohol administration on concentration of malondialdehyde (MDA), glutathione (GSH) and ascorbic acid in testes (phase II study)

(Mean values with their standard errors of six guinea pigs in each group)

\begin{tabular}{|c|c|c|c|c|c|c|c|c|c|c|}
\hline \multirow[b]{2}{*}{ Parameters } & \multicolumn{2}{|c|}{ C } & \multicolumn{2}{|c|}{$\mathrm{C}+\mathrm{AA}$} & \multicolumn{2}{|c|}{ E } & \multicolumn{2}{|c|}{ EAG } & \multicolumn{2}{|c|}{$\mathrm{E}+\mathrm{AA}$} \\
\hline & Mean & SEM & Mean & SEM & Mean & SEM & Mean & SEM & Mean & SEM \\
\hline Testicular MDA (mm/100 g tissue) & $1 \cdot 28^{\mathrm{a}}$ & 0.02 & $1.41^{\mathrm{a}}$ & 0.02 & $3.09^{b}$ & 0.09 & $2 \cdot 35^{\mathrm{c}}$ & 0.06 & $1.63^{\mathrm{a}}$ & 0.02 \\
\hline Testicular GSH (mm/100 g tissue) & $4 \cdot 16^{\mathrm{a}}$ & 0.23 & $4 \cdot 23^{a}$ & 0.20 & $1.86^{\mathrm{b}}$ & $0 \cdot 14$ & $2.57^{\mathrm{C}}$ & 0.18 & $3.31^{d}$ & 0.20 \\
\hline Ascorbic acid (mg/100 g tissue) & $4.95^{\mathrm{a}}$ & 0.27 & $6.54^{b}$ & 0.35 & $2.95^{\mathrm{c}}$ & 0.21 & $3.90^{d}$ & 0.25 & $5 \cdot 00^{\mathrm{a}}$ & 0.30 \\
\hline
\end{tabular}

C, control group; C+AA, control + ascorbic acid group; E, ethanol-treated group; EAG, ethanol abstention group; $\mathrm{E}+\mathrm{AA}$, ascorbic acid-supplemented group. ${ }_{a, b, c, d}$ Mean values within a row with unlike superscript letters were significantly different $(P<0.05)$. 

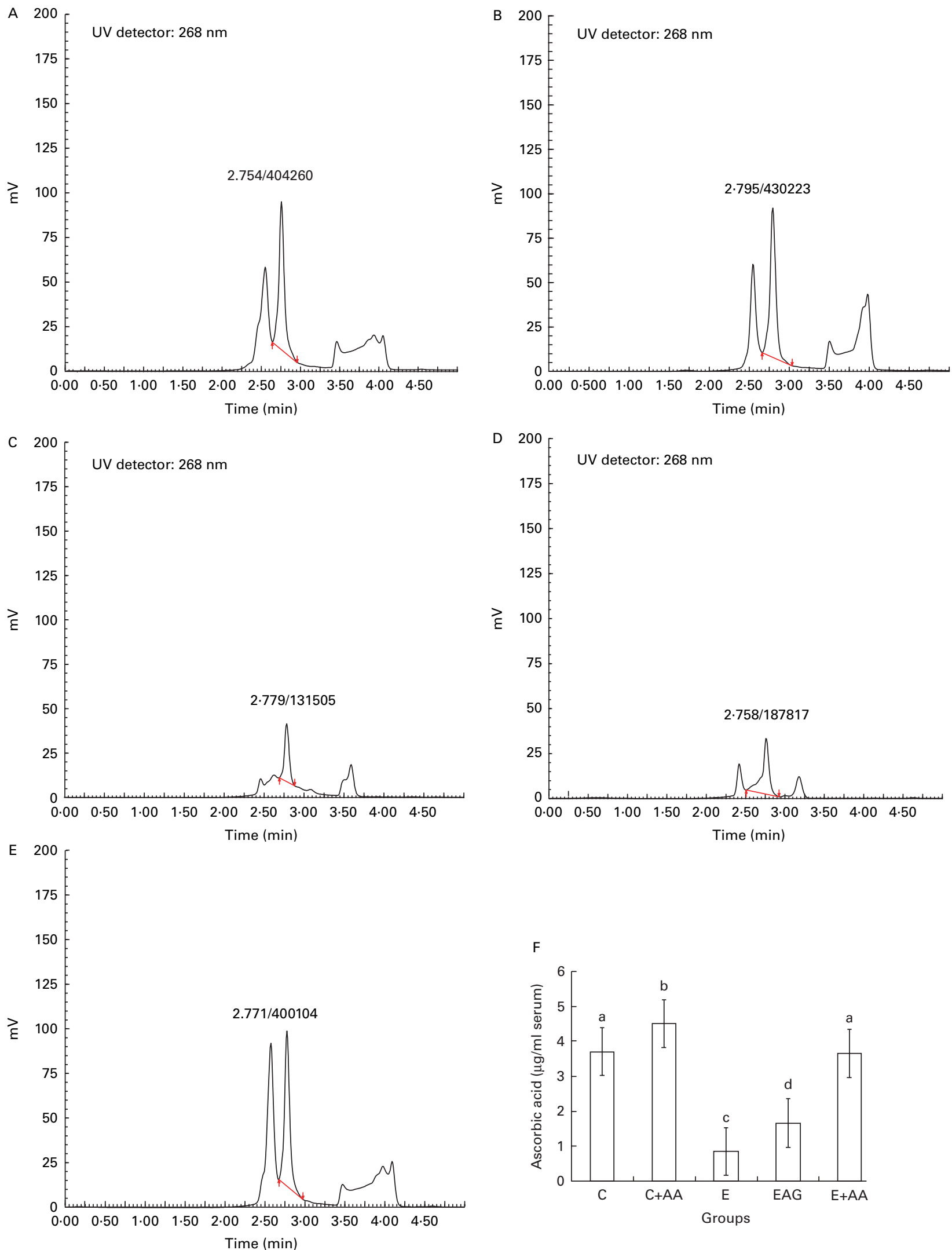

Fig. 4. HPLC chromatograms of ascorbic acid in serum. (A) C, control group; (B) $C+A A$, control + ascorbic acid group; (C) E, ethanol-treated group; (D) EAG, ethanol abstention group; $(E) E+A A$, ascorbic acid-supplemented group. The retention time was 2.7 min. (F) Graphical representation of ascorbic acid content in the serum. Values are means, with their standard errors of six guinea pigs in each group represented by vertical bars. ${ }^{\mathrm{a}, \mathrm{b}, \mathrm{c}, \mathrm{d}}$ Mean values with unlike letters were significantly different $(P<0.05)$. (A colour version of this figure can be found online at http://www.journals.cambridge.org/bjn). 
Table 6. Effect of ascorbic acid supplementation and abstention after alcohol administration on serum testosterone levels, luteinising hormone (LH) and follicle-stimulating hormone (FSH) (phase II study)

(Mean values with their standard errors of six guinea pigs in each group)

\begin{tabular}{|c|c|c|c|c|c|c|}
\hline \multirow[b]{2}{*}{ Groups } & \multicolumn{2}{|c|}{$\begin{array}{l}\text { Testosterone } \\
(\mathrm{ng} / \mathrm{ml})\end{array}$} & \multicolumn{2}{|c|}{$\mathrm{LH}(\mathrm{mlU} / \mathrm{ml})$} & \multicolumn{2}{|c|}{$\mathrm{FSH}(\mathrm{mlU} / \mathrm{ml})$} \\
\hline & Mean & SEM & Mean & SEM & Mean & SEM \\
\hline C & $2 \cdot 16^{\mathrm{a}}$ & 0.08 & $1.63^{\mathrm{a}}$ & 0.05 & $0.74^{\mathrm{a}}$ & 0.08 \\
\hline$C+A A$ & $2 \cdot 90^{\mathrm{b}}$ & 0.11 & $1 \cdot 80^{\mathrm{b}}$ & 0.06 & $0.85^{\mathrm{b}}$ & 0.11 \\
\hline $\mathrm{E}$ & $1.60^{\mathrm{C}}$ & 0.06 & $0.60^{C}$ & 0.05 & $0.40^{\mathrm{C}}$ & 0.06 \\
\hline EAG & $1.77^{\mathrm{d}}$ & 0.07 & $0.77^{d}$ & 0.07 & $0.52^{d}$ & 0.07 \\
\hline$E+A A$ & $3.52^{\mathrm{e}}$ & 0.11 & $1.52^{\mathrm{a}}$ & 0.10 & $1.01^{\mathrm{e}}$ & 0.11 \\
\hline
\end{tabular}

C, control group; C+AA, control + ascorbic acid group; E, ethanol-treated group; EAG, ethanol abstention group; $E+A A$, ascorbic acid-supplemented group.

$\mathrm{a}, \mathrm{b}, \mathrm{c}, \mathrm{d}, \mathrm{e}$ Mean values within a column with unlike superscript letters were significantly different $(P<0.05)$.

water-soluble antioxidant by virtue of its high reducing power and acts as a cofactor for enzymes involved in the biosynthesis of collagen, carnitine and neurotransmitters, and quenches a variety of reactive oxygen species and reactive nitrogen species in the aqueous environment ${ }^{(33)}$. Several conditions, such as alcoholism, stress, smoking, infections and various pathological conditions, which increase oxidative stress, deplete the ascorbic acid reserves in the body and demand higher doses of ascorbic acid supplementation ${ }^{(34)}$. The new average daily intake level for human subjects that is sufficient to meet the nutritional requirement of ascorbic acid or RDA for adults ( $>19$ years) are $90 \mathrm{mg} / \mathrm{d}$ for men and $75 \mathrm{mg} / \mathrm{d}$ for women $^{(35)}$. We initially carried out a dose-response study to find the effective dose of ascorbic acid required to reduce alcohol-induced testicular alteration in guinea pigs. Further investigations were done using the selected dose to analyse the impact of ascorbic acid supplementation on ethanolinduced reproductive toxicity in male guinea pigs and also to compare it with abstention.

The dose-response study revealed that a dose of $25 \mathrm{mg}$ $100 \mathrm{~g}$ b.wt. of ascorbic acid showed the maximum effect in regression of alcohol-induced testicular toxicity by bringing down MDA levels and restoring the sperm count to nearnormal levels. The activity of the toxicity marker, GGT, in serum was also significantly reduced and was brought to a near-normal level by supplementing $25 \mathrm{mg} / 100 \mathrm{~g}$ b.wt of ascorbic acid. Hence, this dose was non-toxic and was selected for further studies.

The progression and regression of alcohol-induced toxicity were evaluated by the assay of GGT in the serum, a marker for ethanol-induced toxicity on a weekly basis. Both ascorbic acid supplementation and abstention could reduce the toxicity induced by alcohol, but a faster recovery was recorded in the case of ascorbic acid supplementation, indicating the role of ascorbic acid as a therapeutic agent to reduce alcohol-induced damage. This reduction in toxicity was also reflected in body weight gain and an increased relative organ weight of testes in the ascorbic acid-supplemented group, as compared with abstention.

The testicular MDA levels were elevated and levels of nonenzymatic antioxidants like GSH in testes and ascorbic acid levels in testes and plasma were diminished in alcohol- administered animals, suggesting a state of oxidative stress in testes. GSH and ascorbic acid are lines of defence against oxidative damage and facilitate protection against ethanol-induced reactive oxygen species production. Depletion in antioxidants enhances oxidative stress in testes. This is in agreement with the study of Grattagliano et $a l .{ }^{(7)}$. Ascorbic acid supplementation was able to reduce the oxidative stress induced by chronic alcoholic intake by reducing the enhanced levels of MDA and by alleviating the depleted levels of GSH and ascorbic acid. Abstention could also lower oxidative stress, but to a smaller extent when compared with the ascorbic acid-administered group. The observation in the present study is in line with our ${ }^{(36)}$ previous reports that supplementation of ascorbic acid reduced the depletion of GSH in the liver caused by the administration of ethanol. Hence, reduction in oxidative stress caused by alcohol may be one of the mechanisms of ascorbic acid to provide a protective effect against alcohol-induced toxicity.

Table 7. Effect of ascorbic acid supplementation and abstention after alcohol administration on testicular sorbitol dehydrogenase (SORD), fructose,

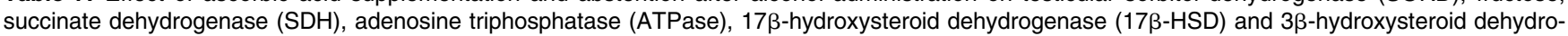
genase (3ß-HSD) (phase II study)

(Mean values with their standard errors of six guinea pigs in each group)

\begin{tabular}{|c|c|c|c|c|c|c|c|c|c|c|}
\hline \multirow[b]{2}{*}{ Parameters } & \multicolumn{2}{|c|}{ C } & \multicolumn{2}{|c|}{$C+A A$} & \multicolumn{2}{|c|}{$\mathrm{E}$} & \multicolumn{2}{|c|}{ EAG } & \multicolumn{2}{|c|}{$E+A A$} \\
\hline & Mean & SEM & Mean & SEM & Mean & SEM & Mean & SEM & Mean & SEM \\
\hline SORD (units*/mg protein) & $2 \cdot 71^{\mathrm{a}}$ & 0.09 & $2 \cdot 87^{\mathrm{a}}$ & $0 \cdot 10$ & $1 \cdot 25^{\mathrm{b}}$ & 0.11 & $1.43^{\mathrm{b}}$ & 0.09 & $2 \cdot 08^{\mathrm{d}}$ & 0.05 \\
\hline Fructose (mg/ml of seminal plasma) & $2 \cdot 08^{\mathrm{a}}$ & 0.07 & $2 \cdot 18^{\mathrm{a}}$ & 0.08 & $0.78^{\mathrm{b}}$ & 0.03 & $1 \cdot 19^{\mathrm{c}}$ & 0.04 & $1.51^{\mathrm{d}}$ & 0.05 \\
\hline $\mathrm{SDH}$ ( $\mu \mathrm{g}$ formazon formed/mg protein per $15 \mathrm{~min}$ ) & $8 \cdot 32^{\mathrm{a}}$ & 0.02 & $8 \cdot 37^{a}$ & 0.01 & $5 \cdot 20^{\mathrm{b}}$ & 0.03 & $6 \cdot 56^{\mathrm{c}}$ & 0.02 & $7 \cdot 94^{\mathrm{a}}$ & 0.03 \\
\hline $\begin{array}{l}\text { ATPase ( } \mu \mathrm{mol} \text { inorganic phosphate released } / \mathrm{mg} \text { protein per } \\
30 \mathrm{~min})\end{array}$ & $5 \cdot 47^{\mathrm{a}}$ & 0.20 & $5 \cdot 66^{\mathrm{a}}$ & 0.21 & $3 \cdot 65^{\mathrm{b}}$ & $0 \cdot 13$ & $4 \cdot 23^{\mathrm{C}}$ & $0 \cdot 16$ & $4 \cdot 96^{d}$ & 0.18 \\
\hline $17 \beta$-HSD (units $\uparrow / m g$ protein) & $1 \cdot 67^{\mathrm{a}}$ & 0.07 & $1 \cdot 78^{a}$ & 0.07 & $0.62^{b}$ & 0.05 & $0.79^{c}$ & 0.05 & $1 \cdot 14^{\mathrm{d}}$ & 0.06 \\
\hline $3 \beta-H S D$ (units $+/ m g$ protein) & $7 \cdot 40^{\mathrm{a}}$ & 0.32 & $7 \cdot 63^{\mathrm{a}}$ & 0.32 & $4 \cdot 21^{\mathrm{b}}$ & 0.21 & $5.33^{\mathrm{c}}$ & 0.22 & $6 \cdot 04^{d}$ & 0.22 \\
\hline
\end{tabular}

C, control; E, ethanol-treated group; C + AA, control + ascorbic acid-treated group; EAG, ethanol abstention group; $\mathrm{E}+\mathrm{AA}$, ascorbic acid-supplemented group.

a,b,c,d Mean values within a row with unlike superscript letters were significantly different $(P<0.05)$.

${ }^{*} \mu \mathrm{g}$ of fructose liberated $/ \mathrm{min}$ at $37^{\circ} \mathrm{C}$.

$\dagger$ Change in absorbance of $0.001 / \mathrm{min}$ at $340 \mathrm{~nm}$. 
Ethanol administration reduced circulating testosterone levels. This may be due to the decreased activities of the major steroidogenic enzymes, $3 \beta-H S D$ and $17 \beta-H S D$, involved in testosterone biosynthesis in the ethanol-treated group. This is in accord with the studies of Maneesh et al. ${ }^{(37)}$. The reduction in testosterone levels can also be attributed to a suppressed hypothalamic-pituitary-gonadal axis, as there was a significant decrease in circulating $\mathrm{LH}$ and FSH levels in ethanol-administered animals. This is in agreement with the observation of Salonen \& Huhtaniemi ${ }^{(38)}$. Ascorbic acid plays a key role in the synthesis of testosterone ${ }^{(39)}$, and ascorbic acid deficiency can affect testosterone synthesis in testes. In the present study, ascorbic acid supplementation increased the activities of the steroidogenic enzymes, $3 \beta$ HSD and $17 \beta-H S D$, and also elevated serum testosterone, LH and FSH levels. However, abstention could not significantly restore the steroidogenic enzyme activities and circulating testosterone, LH and FSH levels, as compared with the ascorbic acid-supplemented group.

The quality of semen in ethanol-treated groups deteriorated as sperm parameters like percentage motility, viability and count were significantly reduced. There was a significant impairment in the morphology of sperm, as the percentage of abnormal sperms increased on excessive alcohol consumption. A low testosterone concentration may be responsible for the adverse effects of ethanol on sperm parameters, as a high level of testosterone in testes is critically required for normal spermatogenesis, development and maintenance of sperm morphology and normal physiology of seminiferous tubules $^{(40,41)}$. The diminution of sperm parameters was restored by ascorbic acid supplementation. The findings are in agreement with studies of Ganaraja et al. ${ }^{(42)}$. Abstention from alcohol was also able to revive the sperm parameters. However, the reversal was more pronounced in the ascorbic acid-supplemented group than with abstention.

Fructose is a main source of energy for sperm motility. Fructose is produced from sorbitol by the coordinated function of SORD and serves as an energy source for spermatozoa $^{(43,44)}$. The ethanol-treated animals showed a decrease in fructose content and SORD activity. This accounts for the reduced sperm motility in the ethanol-loaded groups. There were significant increases in fructose content and SORD activity on ascorbic acid supplementation, which further improved sperm quality. Abstention could not substantially increase the concentration of fructose and SORD activity, as compared with the ascorbic acid-supplemented group.

$\mathrm{SDH}$ is a key enzyme in the mitochondrial Kreb's cycle, which is mainly concerned with the aerobic oxidation of acetyl COA and the generation of ATP. A decrease in SDH activity in the testes of ethanol-ingested guinea pigs indicates a reduction in aerobic oxidation, which could be the result of reduced oxygen transport to tissues ${ }^{(45)}$. Reduced aerobic oxidation and ATP generation in the testes could be responsible for the reduction in ATPase activity. Decreased SDH and ATPase activity with reduced fructose levels could explain the reduced sperm count and motility and the increased number of non-viable spermatozoa observed in the ethanoladministered animals. Ascorbic acid supplementation restored both SDH and ATPase activity, which accounts for the restoration of diminished sperm quality in the ascorbic acidsupplemented group. Abstention from alcohol was able to increase SDH and ATPase activity, but was less significant when compared with the ascorbic acid-supplemented group.

\section{Conclusion}

The present study demonstrates that ascorbic acid supplementation causes a reduction of alcohol-induced testicular toxicity to a greater extent than abstention. The mechanism may be by reducing oxidative stress and improving antioxidant status, which eventually change the microenvironment of testes and enhance the energy needed for motility of sperms, improve the sperm morphology and increase the testosterone levels. The increase in testosterone levels may be due to increased steroidogenic enzyme activities and elevated levels of $\mathrm{LH}$ and FSH of the hypothalamic-pituitary-gonadal axis. In short, therapeutic supplementation of ascorbic acid is effective in minimising the alterations produced by alcohol-induced testicular damage. Further studies are needed to complement and extrapolate the findings of the study to human subjects.

\section{Supplementary material}

To view supplementary material for this article, please visit http://dx.doi.org/10.1017/S0007114512005739

\section{Acknowledgements}

Financial assistance in the form of a Research Fellowship in Science to Meritorious Students sponsored by UGC to R. H. is gratefully acknowledged. R. H. designed and performed the experiment, analysed the data and prepared the manuscript; P. A. A. performed the experiment and helped in drafting the manuscript; S. S. D. analysed the data; P. P., S. R., F. J. and S. K. performed the biochemical assays. M. I. was responsible for the very concept and design of the experiment and interpretation of the data. All authors read and approved the final manuscript. The authors declare that they have no conflicts of interest.

\section{References}

1. Anderson RA Jr, Willis BR, Oswald C, et al. (1983) Male reproductive tract sensitivity to ethanol: a critical overview. Pharmacol Biochem Behav 18, Suppl. 1, 305-310.

2. Arackal BS \& Benegal V (2007) Prevalence of sexual dysfunction in male subjects with alcohol dependence. Indian J Psychiatry 49, 109-112.

3. Bannister P \& Losowsky MS (1987) Ethanol and hypogonadism. Alcohol Alcohol 22, 213-217.

4. Vanthiel DH, Gavaler JS, Lester R, et al. (1975) Alcohol induced testicular atrophy: an experimental model for hypogonadism occurring in chronic alcoholic man. Gastroenterology 69, 326-332.

5. Ylikahri R, Huttunen M, Harkonen M, et al. (1974) Hangover and testosterone. Br Med J 2, 445.

\footnotetext{
a
} 
6. Mendelson JM, Ellingboe J, Mello NK, et al. (1978) Effects of alcohol on plasma testosterone and luteinizing hormone levels. Alc Clin Exp Res 2, 255-258.

7. Grattagliano I, Vendemiale G, Errico F, et al. (1997) Chronic ethanol intake induces oxidative alterations in rat testis. $J A p p l$ Toxicol 17, 307-311.

8. Aitken RJ \& Roman SD (2008) Antioxidant systems and oxidative stress in the testes. Oxid Med Cell Longev 1, 15-24.

9. Schlorff EC, Husain K \& Somani SM (1999) Dose and time dependent effects of ethanol on antioxidant system in rat testes. Alcohol 18, 203-214.

10. Chinoy NJ (1978) Ascorbic acid turn over in animal and human tissue. I Anim Morphol Physiol Silver Jubilee Volume 69-85.

11. Agarwal A, Prabakaran SA \& Said TM (2005) Prevention of oxidative stress injury to sperm. J Androl 26, 654-660.

12. Eskenazi B, Kidd SA, Marks AR, et al. (2005) Antioxidant intake is associated with semen quality in healthy men. Hum Reprod 20, 1006-1012.

13. Sonmez M, Turk G \& Yuce A (2005) The effects of ascorbic acid supplementation on sperm quality, lipid proxidation and testosterone levels of male Wistar rats. Theriogenology 63, 2063-2072.

14. Makker K, Agarwal A \& Sharma R (2009) Oxidative stress, male infertility. Indian J Med Res 129, 357-367.

15. Susick RL Jr, Abrams GD, Zurawski CA, et al. (1986) Ascorbic acid chronic alcohol consumption in the guinea pig. Toxicol Appl Pharmacol 84, 329-335.

16. Abhilash PA, Harikrishnan R \& Indira M (2012) Ascorbic acid supplementation down-regulates the alcohol induced oxidative stress, hepatic stellate cell activation, cytotoxicity and mRNA levels of selected fibrotic genes in guinea pigs. Free Radic Res 46, 204-213.

17. Nishikimi M, Kawai T \& Yagi K (1992) Guinea pigs possess a highly mutated gene for L-gulono-gamma-lactone oxidase, the key enzyme for L-ascorbic acid biosynthesis missing in this species. J Biol Chem 267, 21967-21972.

18. Hume CW (1972) The UFAW Handbook on the Care and Management of Laboratory Animals. Edinburgh/London: Churchill Livingstone.

19. Green CR, Watts LT, Kobus SM, et al. (2006) Effects of chronic prenatal ethanol exposure on mitochondrial glutathione and 8-iso-prostaglandin F2alpha concentrations in the hippocampus of the perinatal guinea pig. Reprod Fertil Dev 18, 517-524.

20. World Health Organization (1999) Laboratory Manual for the Examination of Human Semen and Semen-Cervical Mucus Interaction, 4th ed., pp. 1-50. Cambridge, New York: Cambridge University Press.

21. Reitman S \& Frankel SA (1957) Colorimetric method for determination of serum glutamic oxaloacetic and glutamic pyruvic transaminases. Am J Clin Pathol 28, 56-63.

22. Szaz G (1969) A kinetic photometric method for serum gamma-glutamyl transpeptidase. Clin Chem 15, 24-26.

23. Ohkawa H, Ohishi N \& Yagi K (1979) Assay of lipid peroxide in animal tissue by thiobarbituric acid reaction. Anal Biochem 95, 351-358.

24. Patterson JW \& Lazarow A (1959) Determination of glutathione. In Methods of Biochemical Analysis, pp. 259-279 [D Glick, editor]. New York: Interscience.

25. Roe JH \& Kuether CA (1943) The determination of ascorbic acid in whole blood and urine through 2,4-dinitrophenyl hydrazine derivatives of dehydroascorbic acid. $J$ Boil Chem 147, 399-407.
26. Beatty CH, Basinger GM, Dully CC, et al. (1966) Comparison of red and white voluntary skeletal muscle of several species of primates. J Histochem Cytochem 14, 590-600.

27. Quinn PJ \& White IG (1968) Distribution of adenosine triphosphatase activity in ram and bull spermatozoa. $J$ Reprod Fertil 15, 449-452.

28. Wootton IDP (1964) Micro Analysis in Medical Biochemistry, 4th ed., pp. 104. London: J \& A Churchill Ltd. Glorecester Place.

29. Karvonen MJ \& Malm M (1955) Colorimetric determination of fructose with indole. Scand J Clin Lab Invest 7, 305-307.

30. Lowry $\mathrm{OH}$, Rosebrough NJ, Farr AL, et al. (1951) Protein measurement with the folin phenol reagent. $J$ Biol Chem 193, 265-275.

31. Shivanandappa T \& Venkatesh S (1997) A colorimetric assay method for 3-beta-hydroxy-delta 5-steroid dehydrogenase. Anal Biochem 254, 57-61.

32. Jarbak J (1969) Soluble $17 \beta$-hydroxy steroid dehydrogenase of human placenta. In Methods in Enzymology, vol. 30, pp. 746-752 [SP Colowick and NO Kaplan, editors]. New York: Academic Press.

33. Food and Nutrition Board (2000) Dietary Reference Intakes for Vitamin C, Vitamin E, Selenium and Carotenoids. Washington, DC: National Academy Press.

34. Naidu KA (2003) Vitamin C in human health and disease is still a mystery? An overview. Nutr J 2, 7.

35. Frei B \& Trabe MG (2006) The new US dietary reference intakes for vitamins $\mathrm{C}$ and E. Redox Rep 6, 5-9.

36. Abhilash PA, Harikrishnan R \& Indira M (2012) Ascorbic acid supplementation causes faster restoration of reduced glutathione content in the regression of alcohol-induced hepatotoxicity in male guinea pigs. Redox Rep 17, 72-79.

37. Maneesh M, Jayalekshmi H, Dutta S, et al. (2005) Effect of chronic ethanol administration on testicular antioxidant system and steroidogenic enzyme activity in rats. Indian J Exp Biol 43, 445-449.

38. Salonen I \& Huhtaniemi I (1990) Effects of chronic ethanol diet on pituitary-testicular function of the rat. Biol Reprod 42, 55-62.

39. Biswas NM, Chaudhuri A, Sarkar M, et al. (1996) Effect of ascorbic acid on in vitro synthesis of testosterone in rat testis. Indian J Exp Biol 34, 612-613.

40. Sharpe RM, Donachie K \& Cooper I (1988) Re-evaluation of the intratesticular level of testosterone required for quantitative maintenance of spermatogenesis in the rat. J Endocrinol 117, 19-26.

41. Sharpe RM, Maddocks S, Millar M, et al. (2002) Testosterone and spermatogenesis: identification of stage dependent, androgen-regulated proteins secreted by adult rat seminiferous tubules. J Androl 13, 172-184.

42. Ganaraja B, D'souza Crystal D, Vijayalekshmi BM, et al. (2008) Use of vitamin C on effect of ethanol induced lipid peroxidation in various tissues, sperm count and morphology in the wistar rats. J Chin Clin Med 3, 627-632.

43. Frenkel G, Peterson RN \& Freund M (1975) Oxidative and glycolytic metabolism of semen components by washed guinea pig spermatozoa. Fertil Steril 26, 144-147.

44. King TF \& Mann T (1959) Sorbitol metabolism in spermatozoa. Proc Roy Soc B 151, 226-243.

45. Romero FJ, Bosch-Morell F, Romero MJ, et al. (1998) Lipid peroxidation products and antioxidants in human disease. Environ Health Perspect 106, Suppl. 5, 1229-1234. 